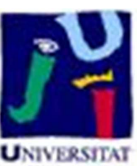

Título artículo / Títol article: Integration of Environmental Models in Spatial Data Infrastructures: A Use Case in Wildfire Risk Prediction

Autores / Autors

Sergio Trilles, Pablo Juan, Laura Díaz, Pau Aragó, Joaquín Huerta

Revista:

Selected Topics in Applied Earth

Observations and Remote Sensing, IEEE

Journal of

Versión / Versió:

Versió post-print

Cita bibliográfica / Cita bibliogràfica (ISO 690):
TRILLES, Sergio, et al. Integration of Environmental Models in Spatial Data Infrastructures: A Use Case in Wildfire Risk Prediction. IEEE Journal on Selected Topics in Applied Earth Observations and Remote Sensing, 2013, vol. 6, no 1, p. 128138.

url Repositori UJI: 


\title{
Integration of environmental models in spatial data infrastructures: a use case in wildfire risk prediction
}

\author{
Sergio Trilles ${ }^{1}$, Pablo Juan ${ }^{2}$, Laura Díaz ${ }^{1}$, Pau Aragó ${ }^{1}$, Joaquín Huerta ${ }^{1}$ \\ Institute of New Imaging Technologies ${ }^{1}$ \\ Department of Mathematics ${ }^{2}$ \\ Universitat Jaume I \\ Castelló de la Plana, Spain \\ Email: \{strilles,juan,ldiaz,parago,huerta\}@uji.es
}

This is an author version of this article; S. Trilles, P. Juan, L. Diaz, P. Arago, i J. Huerta, Integration of Environmental Models in Spatial Data Infrastructures: A Use Case in Wildfire Risk Prediction, IEEE Journal of Selected Topics in Applied Earth Observations and Remote Sensing, vol. PP, nm. 99, p. 1 -11, 2013. D.O.I:10.1109/JSTARS.2012.2236538. Final version can be found ahttp://ieeexplore.ieee.org/xpl/articleDetails.jsp?reload=true\&arnumber=6415305

\begin{abstract}
Achieving sustainable growth in our society implies monitoring our environment in order to measure human impact and detect relevant changes and detrimental driving factors such as wildfires and desertification. In order for experts to perform environmental modelling they need to be able to access data and models in an efficient and interoperable manner as well as share their findings to assist other professionals in decision making. In the current information society, distributed information systems are essential for sharing digital resources such as data and tools. Advances in Service-Oriented Architectures (SOA) allow for the distribution and accessibility of on-line resources such as data and tools, which served through standards-based services improve the sharing of data, models and models results.

This research presents a service-oriented application that addresses the issues of interoperable access to environmental modelling capabilities as well as the mechanisms to share their results an efficiently throughout interoperable components. The aim is twofold, first we present different models for multi-scale forest fire risk prediction based on spatial point processes, and second we provide this functionality as a distributed application, that, based on international standards, such as those offered by the Open Geospatial Consortium (OGC), improves interoperable access to these models as well as the publication of the results to be shared with other interested stakeholders.
\end{abstract}

\section{Index Terms}

Risk prediction, disaster management, forest fire, wildfire, geoprocessing, spatial information system, multi-scale forest fire prediction, spatial point processes

\section{INTRODUCTION}

Today, wildfires are one of the main problems for the conservation of the Mediterranean forests and to prevent the desertification in this region [1],[2]. Forest destruction produces a detrimental impact on the environment, for instance, in recent years forest areas have lost large amounts of hectares (Spain wildfires in 2005: 25.492 fires and 188.697 acres burned) in Spain due to the wildfire events [3]. If we analyze burned forests areas in Spain, we can obtain an overview of the wildfire 
problem [3], which leads to the destruction of forests and their biodiversity [4], the loss of soil conservation [1],[2] and even worse the loss of life. This situation leads to the transformation of a forest area into a bush area due to a process of soil loss and desertification.

The mitigation of forest fires requires a forest management plan to conserve forests, reduce the impact of fires and to facilitate fire fighting [5]. The design of forest fire models is a starting point for designing preventive actions [6],[7], followed by the means to share the capacity of this analysis so as to compare results and take actions [8].

The preservation of forested areas is very important in the Mediterranean, as they are an important source of biodiversity and soil conservation for the proper functioning of our life cycle that directly affects the world economy [1]. Natural fires caused by factors such as thunderstorms and dry seasons do not affect the planet's ecological balance as they are part of the life cycle of a forest and cause partial or total regeneration of species [1],[5]. Nevertheless, natural fires are only a small portion of all the wildfires that occur in the Mediterranean regions. Forest fires are mostly caused by human factors [3],[9] that can be reduced by modelling and by being aware of fire risk in certain areas.

There is a lot of research work dedicated to the study of forest fires, due to its interest within the scientific community and because it has a direct impact on the economic and social aspects of the affected regions. As we briefly introduced above, forest fire monitoring work can be divided into two branches [9]:

- Fire simulation: used to predict the progress of a wildfire in real-time. This is based on physical conditions, weather and human factors. This helps us to improve the effectiveness and reduce the risk of forest fire extinction actions.

- Fire risk analysis: it provides risk analysis maps for each region. This is based on physical conditions, weather and human factors. This approach is more useful for forest fire prevention actions. Our work continues along this research line, where we will propose a novel method and its results in forest fire risk analysis and its interoperable accessibility.

There are different models dedicated to the study of forest fires. In the different literature devoted to this topic there are models which simulate fire by taking into account its behaviour. There are fire simulation models which try to predict fire behaviour, which is considered continuous and uniform [10],[5] taking into account some parameters such us terrain slope, wind direction, strength and a combustible model [11],[12]. This approach requires an ignition point and output goodness depending on the input data resolution both in space and time. However it requires collecting lot of ignitions points to cover an area which turns the prediction of fires a huge task. Another approach is to create maps to show the risk of forest fire to manage prevention works and effective surveillance [6]. This approach takes into account weather conditions and combustible conditions [13]. We can find this kind of modelling for instance in the European Forest Fire Information System [14]. Forest fires historical databases allow for estimation and the use of models to generate a risk map [15]. The statistical analysis of fire prediction is useful in forest fire prevention, to plan preventive actions for minimizing the consequences of wildfires [9]. Statistical approach is the basis for the forestry application designed and implemented in this paper.

Many studies have been conducted to generate measures of fire risk, for instance [16]. Some of the input parameters in these models are: terrain slope and aspect, tree density, species composition and land use. These variables have a direct relationship with wildfires [17],[18]. Another factor is weather conditions since climate variables such as temperature and wind speed seem to be directly influencing wildfire risk and its behaviour [19]. The introduction of temperature or humidity is consistent with 
advances in point processes studies that are a new field to be explored in the future.

The seasonality of the fire is determined by two factors. One of them is natural causes [20], the other one is human causes [21]. In the case of natural causes, the wildfire risk depends on two factors such as:

- Climatic conditions [22],[23].

- Type and structure of vegetation [24] that in some cases favors the burning and other cases seems to slow its progression [25].

- Socioeconomic conditions [26],[27].

[28] define environmental models for fire risk prediction; these models have been integrated into the presented system [29]. In this paper we go beyond these factors and we present a model that performs fire risk analysis by also taking into account the type and structure of the terrain: factors such as the slope, the orientation, land use and elevation will be introduced as separated covariates separated in the models. We work with daily, monthly or yearly data.

Environmental experts such as forestry experts need to efficiently access and share not only data resources, but also these modelling capacities to generate new information that assists in decision-making. Therefore, our second goal in this paper is to share this model functionality and thereby allow it to be accessible and reusable by different stakeholders. In the geospatial domain, Spatial Data Infrastructures (SDI), offer the capability of discovering, accessing and sharing geospatial resources among a wide range of actors at different scales [30],[31].

SDI comprises a set of policies and standard activities promoting the creation of spatial information services to assist diverse user communities in collecting, sharing, accessing and exploiting spatial resources [32],[33]. The current trend in environmental applications is to deploy applications on top of SDIs accessing resources via standard web services that are effective, simple to use and available in an ad hoc manner, [8] promoting interoperability [34].

In the SDI community, however, we have identified two main issues to be addressed to provide users with useful environmental applications such as those that perform forest fire risk prediction: First, the lack of on-line modelling capacities that must be supplied by other means such as desktop applications [8] and second, the lack of mechanisms to facilitate the publication of the results to be shared with other stakeholders [35].

Interoperability, within the geospatial community, is improved through standardization efforts mostly coming from the Open Geospatial Consortium 1 (OGC) which is responsible for defining standard interface specifications for spatial services to ensure the interoperability of data and models across a distributed network [34]. The existing specifications have been proven to help in setting up interoperating spatial services to share distributed spatial resources [36]. For instance, the OGC Web Processing Service (WPS) [37] specifies an interface for accessing processing functionality as distributed web services. It provides an interface to describe any computation (process) and the communication protocol to send service requests and retrieve model results [37].

WPS specification is generally defined to provide standard-based access to a wide variety of calculations of spatial data using Web Services. A WPS-based service can offer operations to treat both, vector and raster data, which is available locally on the server or distributed throughout the Internet. The WPS specification provides three operations: GetCapabilities, DescribeProcess

\footnotetext{
${ }^{1}$ http://www.opengeospatial.org/
} 
and Execute.

The use of standard-based interfaces for web services such as Web Processing Services is for interoperability. Currently, this functionality can be available through a well-known interfaced service, which allows it to be invoked and reused in different scenarios. Processes are run at the server, so there is no need to install or store anything locally. However, the use of standardbased services and service oriented architectures to build applications make the application more complex. The applications have to consider the implementation of user-friendly client sides so users can interact transparently with the functionality. These client applications can be a desktop, a web or even a mobile application.

Related work deploying distributed capacities on top of SDI can be found in the work of [38] who argues that WPSbased services are suitable for geospatial calculations. [39],[40] describe geospatial data modelling deployed on top of SDI to provide users with access to data and models implemented as OGC-based services aiming at increasing the interoperability and reusability of the components. [8] describe an environmental monitoring SDI-based application, in the hydrology domain. More recently in the forestry domain, [41] describe a web portal which provides access to an SDI offering forest resources data at a variety of spatial scales as well as providing analytical capabilities for monitoring and validating forest change. This Web application deployed on a forestry-oriented SDI provides standardized components, in particular an assessment of protected areas affected by forest fires as an interoperable processing service implemented as a WPS.

In this direction, this paper initially describes a multi-scale forest fire risk prediction model implemented as a distributed application. This application provides a novel methodology to predict fire risk. Secondly, it presents the provision of these models as a standard-based service to be reused in other scenarios together with the capacity to publish in interoperable modelling results to be shared, so that users are able to compare methodologies, areas and scales for validation and calibration within their own experiments.

Our objective is to demonstrate how to improve the accessibility to fire risk model capabilities by using SDI principles to facilitate the sharing and comparison of methods and results to assist in forest fire prevention plans.

\section{Materials: Forest Fire Risk Prediction Data}

According to the system requirements, we have defined seven input parameters that include: area (polygon to analyze), forest fire location, slope, land use, orientation, elevation and model number.

This historical forest fire data have been collected by the forest fire prevention office from the Generalitat Valenciana, Spain. Environmental agents survey all the fire events registering their location, perimeter and weather conditions. For our models we have used the centroids of the fire events instead of the perimeter. Other data feeding the models is the Corine Land Cover (CLC) 2006 [42] vector layer form from Instituto Geográfico Nacional, which provides information about the land use coverage. Digital terrain model with a spatial resolution of 200 meters resolution from Instituto Geográfico Nacional has been used to get terrain elevation, terrain slope and orientation.

The area is represented as a set of points that define the area to be tested. The parameters of the forest fire are defined for each point location. Slope is the steepness or degree of inclination of the terrain surface. Slope cannot be directly computed from elevation points; one must first create either a raster or Triangular Irregular Networks (TIN) surface. 
In this paper, the slope for a particular location was computed as the maximum rate of change of elevation between the location and its surroundings using a raster digital terrain model with 200 meters of resolution. The slope was expressed in degrees. Aspect is the orientation of the slope, measured clockwise from 0 to 360 degrees, where 0 is north-facing, 90 is east-facing, 180 is south-facing, and 270 is west-facing. Hill shading is a technique used to visualize terrain such as shaded relief, illuminating it with a hypothetical light source. Here, the illumination value for each raster cell was determined by its orientation to the light source, which, in turn, was based on slope and aspect.

With respect to land use variables, we used the Coordination of Information on the Environment (CORINE) database. The CORINE program was initiated in 1985 by the European Commission and was adopted by the European Environment Agency (EEA) in 1994 [43],[42]. In this paper we reclassified land use into ten categories: coniferous forests; dense forests; pastures; fruit trees and berries; artificial non-agricultural vegetated areas; transitional woodland scrub; scrub; natural grassland; mixed forests; and urban, beaches, sand, bare rocks, burnt areas and water bodies. This program has been developed by the biologist and the workers of the wildfires. It helps the study because it decreases the computational time and the results are the same [28].

The other two input parameters, orientation and elevation have these characteristics for each point of the area that will be analysed.

\section{Methods: Forest Fire Risk Prediction Models}

Next, we define the methodology used to model the fire risk. We use spatial point processes to attain information on fire risk [44],[45]. These kind of processes use a stochastic model that generates an infinite number of events $\left\{x_{i}, \mathrm{i}=1 \ldots \mathrm{n}\right\}$ in a set $X$. If these events have measures or marks associated to them then they will have a point process with marks.

One of the main goals of point processes is to model the fire risk within a defined area. If we associate its spatial coordinates, the longitude and latitude of the centroid of the burned area, along with other variables such as slope, orientation, elevation or land use, and control the timing of the fire we can identify the set of forest fires using a spatio-temporal stochastic process. In this way, having as input parameters the area and number of measurements, we ensure the model to be multi-scale, as it will be useful to predict risk in any resolution scale. In many cases, the point processes theory is used in this way: [46],[47].

\section{A. Models used}

During this research our methodology to model fire risk uses two different spatial point processes. The following subsections will describe each process.

1) Poisson processes: To describe the second-moment properties [48], of a spatial point process, we need some additional notation. Let $d x$ denote a small region containing the point $x$. The (first-order) intensity function of a spatial point process is given by

$$
\lambda(x)=\lim _{|d x| \rightarrow 0}\left\{\frac{E[N(d x)]}{|d x|}\right\},
$$


where $E$ is (4) and the second-order intensity function has the form:

$$
\lambda_{2}(x, y)=\lim _{\substack{|d x| \rightarrow 0 \\|d y| \rightarrow 0}}\left\{\frac{E[N(d x) N(d y)]}{|d x||d y|}\right\}
$$

Second-order properties provide information on the interaction between points in a spatial point pattern, and set a means to test the null hypothesis of Complete Spatial Randomness (CSR) in nest site distribution. They are known to provide the best way to statistically present the distributional information inherent in point patterns and in explaining the correlation between them [49]. Thus, based on this premise we can decide whether a spatial point pattern follows a random, clustered or dispersed distribution pattern or if it does not follow as such.

The process is stationary and isotropic if its statistical properties do not change under translation and rotation, respectively. If we now assume that the process is stationary and isotropic (or homogeneous, for short), the intensity function reduces to a constant, $\lambda$, equal to the expected number of events per unit area. Also, the second-moment intensity is reduced to a function of distance, $\lambda_{2}(x, y)=\lambda_{2}(r)$, where $r=\|x-y\|$ is the distance between $x$ and $y$. In this context, the reduced second moment function of a stationary, isotropic spatial point process is given by

$$
K(r)=2 \pi \lambda^{-2} \int_{0}^{r} \lambda_{2}(s) s d s .
$$

The practical importance of 3 is that the reduced second moment function can be expressed as an expectation of an observable quantity, which in turns suggests how we could estimate it from the data. Indeed,

$$
\lambda K(r)=E(\text { number of events within a distance } r \text { of an arbitrary event) }
$$

where $E(\cdot)$ is the expectation operator. For a completely random pattern, events are positioned independently, hence $K(r)=$ $\pi r^{2}$. This gives a benchmark against which to assess departures from CSR. For aggregated patterns, $K(r)$ is relatively large at small distances, $r$, because each event typically forms part of a cluster of mutually close events. Conversely, for regular patterns $K(r)$ is relatively small at small distances $r$ because each event tends to be surrounded by empty space.

Another useful property is that $K(r)$ is invariant to random thinning, i.e. retention or deletion of events according to a series of independent Bernoulli trials [50].

The homogeneous Poisson process is the simplest point process that represents no underlying process, resulting in complete randomness in wildfire distribution. The $\mathrm{K}$ function proposed by Ripley [51] function of the homogeneous Poisson process is defined as:

$$
K(r)=\frac{1}{A} \sum_{i=1} \sum_{j \neq 1} \frac{\omega_{i j} I\left(d_{i j} \leq r\right)}{\lambda^{2}}
$$

In this function, $A$ denotes the area of the plot; $\lambda$ is wildfire density, $\omega_{i j}$ is an edge correction term, $d_{i j}$ represents the distance between two points, and $I$ is an index function where $I=1$, if $d_{i j}=r$, and $I=0$ otherwise [51]. Wildfire density, 
$\lambda$, is the parameter to be estimated in this model.

The inhomogeneous Poisson process can be used to model the heterogeneous association in wildfires. In this model, relationships between density and heterogeneity are included via a spatially heterogeneous intensity function, $\lambda(s)$ [49]. The $K$ function of the inhomogeneous Poisson process is defined as:

$$
K_{i n h}(r)=\frac{1}{A} \sum_{i=1} \sum_{j \neq 1} \frac{\omega_{i j} I\left(d_{i j} \leq r\right)}{\lambda\left(s_{i}\right) \lambda\left(s_{j}\right)}
$$

where $A, \lambda, \omega_{i j}, d_{i j}$, and $I$ are the same as in the homogeneous Poisson process; and $\lambda\left(s_{i}\right)$ and $\lambda\left(s_{j}\right)$ are the values of the intensity function at points $s_{i}$ and $s_{j}$, respectively.

Specifically, the intensity function, $\lambda(s)$, is modelled as a log polynomial regression:

$$
\lambda(s)=\exp \left(\beta^{T} X(s)\right)
$$

where $X(s)$ is a vector of variables and $\beta^{T}$ is a vector of regression parameters. Two different types of log polynomial regression were used in this study: log linear regression with covariates and log quadratic regression with the coordinates of the wildfire.

2) Area-Interaction processes: As we are interested in modelling aggregated patterns we focus on higher-order interactions and a useful model in this context is the so-called Area-Interaction point process model. The Area-Interaction process [52],[53] with disc radius $r$, intensity parameter $\kappa$ and interaction parameter $\gamma$ is a point process with probability density:

$$
f\left(s_{1}, \ldots s_{n}\right)=\alpha \kappa^{n(s)} \gamma^{(-A(s))}
$$

where $s_{1}, \ldots . s_{n}$ represent the points of the pattern, $n(s)$ is the number of points in the pattern, and $A(s)$ is the area of the region formed by the union of discs of radius $r$ centered at the points $s_{1}, \ldots, s_{n}$. Here, $\alpha$ is a normalizing constant. The interaction parameter $\gamma$ can be any positive number. If $\gamma=1$ then the model is reduced to a Poisson process with intensity $\kappa$. If $\gamma<1$ then the process is regular, while if $\gamma>1$ the process is clustered. Thus, an Area-Interaction process can be used to model either clustered or regular point patterns. Two points interact if the distance between them is less than $2 * r$.

Here, we parameterized the model in a different form [48], which is easier to interpret. In canonical scale-free form, the probability density is rewritten as:

$$
f\left(s_{1} \ldots s_{n}\right)=\alpha \beta^{n(s)} \eta^{(-C(s))}
$$

where $\beta$ is the new intensity parameter, $\eta$ is the new interaction parameter, and $C(s)=B(s)-n(s)$ is the interaction potential.

Here,

$$
B(s)=A(s) /\left(\pi \cdot r^{2}\right)
$$

is the normalized area (so that the discs have unit area). In this formula, each isolated point of the pattern contributes a factor 
$\beta$ to the probability density (so the first order trend is $\beta$ ). The quantity $C(s)$ is a true interaction potential, in the sense that $C(s)=0$ if the point pattern $x$ does not contain any points then it lies close together (closer than $2 r$ units apart).

The old parameters $\kappa$ and $\gamma$ of the standard form are related to the new parameters $\beta$ and $\eta$, of the canonical scale-free form, by:

$$
\beta=\kappa \gamma^{\left(-\pi \cdot r^{2}\right)}=\kappa / \eta
$$

and

$$
\eta=\gamma^{\left(-\pi \cdot r^{2}\right)}
$$

provided $\kappa$ and $\gamma$ are positive and finite [48].

In the canonical scale-free form, the parameter $\eta$ can take any non-negative value. The value $\eta=1$ again corresponds to a Poisson process, with intensity $\beta$. If $\eta<1$ then the process is regular, while if $\eta>1$ the process is clustered. The value $\eta=$ $O$ corresponds to a hard core process with hard core radius $r$ (interaction distance $2 r$ ). The inhomogeneous Area-Interaction process is similar, except that the contribution of each individual point $s_{i}$ is a function $\beta\left(s_{i}\right)$ of location, rather than a constant beta.

\section{B. Pinpointing models}

We introduced the different models that we have used for modelling. In each case we introduced different covariates such as elevation or slope and all possibilities are presented in nine models. We have defined nine different models from previous parameters (Table I).

\section{EXPOSING THE FOREST FIRE RISK MODELS: DESIGN OF THE PROCESSING SERVICES}

In order to benefit from and reuse geospatial resources deployed on SDIs we aim at encapsulating the above mentioned modelling methodologies for fire risk calculation as a distributed processing service to be deployed and exposed as a part of an application on top of an SDI. Following SDI principles, we have designed the processing service to be implemented as a standard-based processing service. The standard of choice is OGC WPS interface specification [37]. A crucial step in the design of a spatial application is defining the input and output parameters in order to be able to link it to other services, for accessing data to feed the application and/or to visualize the results.

\section{A. Modelling the parameters}

According to the fire risk models described in section 3, the following figure illustrates the parameterization of the processes to be deployed as WPS that will expose the models (Fig. 1). The input parameters are the area, forest fire location, slope, land use, orientation and elevation. These input data are codified in Shapefile forma 2 The last entry, the model number, is the model number, is the model number that we run and that is codified as a string.

${ }^{2}$ http://www.esri.com/library/whitepapers/pdfs/shapefile.pdf 
The processing service has two output parameters (Fig. 11); the code that defines each model and graphics for each model's execution. The prediction is associated with a vector point dataset codified according to the KML format ${ }^{3}$, which is an OGC standard and is widely supported by geospatial applications.

\section{B. Architecture of the processing services}

One of the main goals of our work is to facilitate the reuse of the defined scientific models. These algorithms that run locally on a particular workspace are inaccessible to a non-specialized user. During this research we have wrapped and exposed them as standard-based web service facilitating their accessibility.

We have generated a WPS providing the different fire prediction processes. Each one is responsible for running a model using different parameters. The user can choose which set of models is to be run at a time to obtain the fire risk prediction. Each process has common parts that are reused by all the models, such as the treatment of inputs and outputs.

Fig. 2 shows where our project is located according to SDI principles. The INSPIRE Directive [54] defines the European Spatial Information Infrastructure which defines how distributed functionality is deployed as a standard-based service according to an established classification (see top of Fig. 27. As we have described, our fire risk models are wrapped as a processing service, implementing the WPS-based interface. Therefore we will deploy an instance of a WPS implementation providing the predictive models to be accessible by experts that are interested in accessing this functionality to analyze and prevent fire hazards.

Below, we will describe the steps for fire-risk models execution (Fig. 3. In the first step the user can invoke the model by sending a WPS execute request. All parameters are required, so the second step is to verify that all the parameters are correct.

This step internally launches a routine to remove temporary folders of previous executions. This will remove unnecessary temporary files and keep the outputs. Other sub-steps are related to file decompression and generation of the required text files for the $\mathrm{R}$ process. This is a high-time consuming process due to the large size of the input data.

The next step is the calculation of the fire risk statistics; within this step our process calls the process in $\mathrm{R}^{4}$ This can be done using Windows and UNIX operating systems, since our WPS is provided with the required libraries. Furthermore, we perform data transformation of Rprocesses output. The $\mathrm{R}$ output is returned and codified as plain text. We want the output parameter to be interoperable with other GIS applications, so that the WPS runs a data conversion process. We convert this result to be formatted to KML, as it is the chosen format for codified vector data; this format allows the output to be easily created and sent by our WPS implementation.

Finally, the WPS returns the paths of the graphs in each process that are obtained for each model, as the path to the generated KML. These data are hosted on the WPS server and they are accessible via a single URL.

In order to complete the life cycle of information in SDI, our results will be published in standard-based geospatial services to make it available publically. Our aim is to publish the modelling results so that they will be available for future discovery, view and download according to the services classified by INSPIRE as shown in Fig 2. As described in previous work [55], [56] we have designed a publication service able to automatically publish the generated results by the fire prediction models. This 
Publication Service called the GEOSS Service Factory (GSF) [55] aims at maintaining geospatial information infrastructures by assisting users in publishing content in existing data services. The GSF hides the complexity of standard interfaces and offers a unique entry point for content to be delivered. GSF is also implemented as a WPS and is included in the user workflow to publish the resulted data, in this case the fire risk prediction and the graphs. Moreover, it is able to generate and publish the metadata of the data published [56] to improve future searches on the data. The metadata that we generate has the ISO 19139 structure and is published in a metadata catalogue.

\section{RESULts}

In this section, we describe and discuss the experimentation conducted to demonstrate the benefits of our contribution. We have chosen the geographical area of Castellón de la Plana (Spain) as a test area (Fig 44. We have chosen this area for two reasons. The first one is that the province of Castellón is not very large, thus, we can easily adapt to the requirements of the computational and time costs. Secondly, we have historical forest fire spatial information for this area. We have presented the results in this region but they can be created for any region, in a multi-scale basis, i.e., a model can be run for a smaller area such as a province scale or a larger area at a national scale.

For this experiment we executed the processing service for the nine models defined. An important issue was the distance between points in the different parameters because we wanted to observe the interaction between the different points; we found that each point is separated by a distance of 200 meters, which is the same distance of the raster Digital Terrain Model (DTM) resolution. Fig. 5 shows the representation of the system parameters.

The following graphs (Fig. 6) are the results obtained from executing the fire-risk WPS and running the nine fire risk models. By using this point process methodology we can obtain the limitations of the computational issues. In a small region we can have one or even up to ten thousand points, this amount will determine the speed of the process, i.e., whether it will be faster or slower. Further, the error associated will be different. This error depends on the number of points in the region and if the data are incorrect, the models results (Fig. 6) will give us the empirical line outside the minimum and the maximum lines of the models.

In the $\mathrm{X}$ axis of the graphs, the value of $\mathrm{r}$, is as shown the distance between points or fires. The $\mathrm{Y}$ axis shows the value of the L-Function. The L-Function [7] is defined as:

$$
L(r)=\sqrt{K(r) / \pi}
$$

All graphs show four lines: an upper (green), a lower (blue) are the limits of the model, an interior (red) is the average distribution of the simulations. The theoretical value of the model used in each case and the last line that stands above all others is the empirical distribution (black) and it shows the real represented values obtained by the model.

The black colored line allows us to gage the best fire risk prediction model. This line has to fit within the envelopes, the upper and the lower lines. If the empirical line is above the upper limit it means the case is clustered and if the empirical line is below the lower line it means the point process must be modelled as inhibition. The graph above shows us that the 
Area-Interaction method is the best method, because the empirical distribution line is always kept within the enclosure lines. All four methods are good for forest fire risk, but perhaps the better of the four is the model with all covariates.

The fire-risk map is also returned by the modelling service in the form of a point layer encoded in KML format. This map is shown in Fig. 7. Each point in the map has its associated prediction result. Each point of the models result has the ExtendedDataattribute information associated to it.

The results are divided in 20 classes, using the quantile divisional, in order to view the model prediction for each visual form. The following figures (Fig. 8) show the fire risk predictions obtained for each defined model. The table (Table II) shows the results for the models of $\mathrm{R}$ we have enabled for this work.

The Area-Interaction models show a clear improvement over the Poisson model. They provide a good fitting to most of the cases including, unlike the previous models, the Poisson with covariates. Regarding our findings, we conclude that, despite the variability found among covariates, the model that best fits the behaviour of fires for most situations is the Area-Interaction point process model, its results show that the best predictions are Area-Interaction models. The best model is the Area-Interaction with all of the covariates we have used (Fig. 8(i)). The analysis should be completed using other covariates such as wildfire in roads and towns, as well as economic factors such as land prices. We can complete the study by adding new covariants to those proposed without restricting the study. On the other hand, it would also be interesting to introduce some of the meteorological covariates, that we are currently experimenting with, such as temperature, precipitation and wind. The results showed that the fire data point patterns are significantly clustered at different scales and spatial extents through time, revealing that the underlying process consists of first-order trend and second-order clustering rather than pure randomness.

The execution time of the Area-Interaction is greater than the Poisson models; this is because the Area-Interaction models need more operations than Poisson models because their structure is more complex. Area-Interaction models depend on the quantity of parameters that describe the clustering and the inhibition possibilities.

These models have a temporal cost measure in hours. This is not caused by the distribution of the modelling capacities of the standard-based service interfaces or protocols, but the causes of the slow performance is due to statistical models when they execute complex operations for many points. Furthermore, the integration and execution of the R-package to collect and prepare data to be processed is really fast, even when data inputs are very large (100 MB). More temporal features to take into account to manage costs and improve performance are the computer and network characteristics 5

\section{CONCLUSIONS}

In this paper we have presented a methodology to model forest fire risk using different models. In order to share these models and their results we have designed a standard-based distributed application to publish this functionality. Following SDI principles we have wrapped these models as a standard-based geoprocessing service to improve interoperability and provide standard access. In particular, this geoprocessing service wrapping the predictive models implements the WPS standard interface.

The use of standard-based interfaces for web services such as WPS improves interoperability. Now the functionality is available through a well-known interfaced service, which allows it to be invoked and reused in different scenarios. Processes

${ }^{5}$ Features of the computer used: Processor Intel(R) Xeon(R) CPU 5160 @ 3.00GHz Memory RAM 16 GB DDR2 FB-DIMM synchronous 667 MHz. 
are run at the server so there is no need to install and store anything locally. However, the use of standard-based services and service oriented architectures to build applications make the application more complex. Therefore, the applications have to consider the implementation of user-friendly client sides so users can interact transparently with the functionality. These client applications can be a desktop, a web or even a mobile application.

For future work, we are interested in different research lines, such as those related to the interaction of the user with the model. Our aim is to assist users in working more interactively, by being able to select and refine the input parameters such as the model type to be used (Poisson or Area-Interaction) or how many covariates will be needed.

Further improvements of the models might incorporate time by considering space-time point process models. A direct benefit of this approach is modelling and evaluating the corresponding space-time interaction, which is something that we have not considered in the scope of this paper. In this area, we are currently investigating the integration of real-time factors such as climate data. This entails investigating sensor observations services and protocols to be integrated with WPS-based services.

In order to improve the computational time required for model execution a reduction technique point needs to be examined. Asynchronous response techniques as well as the delivery of the results to an e-mail address are other solutions for addressing the temporal cost issues.

We need to investigate suitable mechanisms, standards and protocols, to interact with these geospatial processing services from mobile platforms to improve real time modelling and ubiquitous access to these capacities [57].

\section{ACKNOWLEDGEMENT}

This work has been partially supported by the European FP7 Project nr. 226487 called EuroGEOSS, the GEOCLOUD project reference: IPT-430000-2010-11, subprogram Innpacto 2010, Ministerio de ciencia e innovación and Generalitat Valenciana (Grant ACIF/2012/112). We also would like to thank the Department of Infrastructure Territory and Environment of the Generalitat Valenciana, Section of Forest Fire Prevention for the assignment of geographic data.

\section{REFERENCES}

[1] M. Palahi, R. Mavsar, C. Gracia, and Y. Birot, "Mediterranean forests under focus," International Forestry Review, vol. 10, no. 4, pp. 676-688, Dec. 2008. [Online]. Available: http://www.ingentaconnect.com/content/cfa/ifr/2008/00000010/00000004/art00010

[2] R. Shakesby, "Post-wildfire soil erosion in the mediterranean: Review and future research directions," Earth-Science Reviews, vol. 105, no. 3-4, pp. 71-100, Apr. 2011. [Online]. Available: http://linkinghub.elsevier.com/retrieve/pii/S001282521100002X

[3] M. de Medio Ambiente, "Los incendios forestales en España. decenio 1996-2005," Ministerio de Medio Ambiente, Tech. Rep., 2006.

[4] J. Bengtsson, S. G. Nilsson, A. Franc, and P. Menozzi, "Biodiversity, disturbances, ecosystem function and management of European forests," Forest Ecology and Management, vol. 132, no. 1, pp. 39-50, Jun. 2000. [Online]. Available: http://linkinghub.elsevier.com/retrieve/pii/S0378112700003789

[5] R. Vélez Muñoz, Ed., La defensa contra incendios forestales: fundamentos y experiencias, 2nd ed. Madrid: McGraw Hill, 2009.

[6] J. González-Olabarria and T. Pukkala, "Integrating fire risk considerations in landscape-level forest planning," Forest Ecology and Management, vol. 261, no. 2, pp. 278-287, Jan. 2011. [Online]. Available: http://linkinghub.elsevier.com/retrieve/pii/S0378112710006298

[7] P. Juan, J. Mateu, and M. Saez, "Pinpointing spatio-temporal interactions in wildfire patterns," Stochastic Environmental Research and Risk Assessment, vol. online, no. 0, pp. 1-20, Apr. 2012.

[8] C. Granell, L. Díaz, and M. Gould, "Service-oriented applications for environmental models: Reusable geospatial services," Environmental Modelling and Software, vol. 25, no. 2, pp. 182-198, Feb. 2010. [Online]. Available: http://linkinghub.elsevier.com/retrieve/pii/S1364815209002047 
[9] G. Bianchini, "Wildland fire prediction based on statistical analysis of multiple solutions," Ph.D. dissertation, Universitat Autnoma de Barcelona (Spain), 2006.

[10] R. Rothermel, How to predict the spread and intensity of forest and range fires. Intermountain Forest and Range Experiment Station Ogden, 1983.

[11] D. Molina-Terrén, E. Martínez-López, and D. Garcia-Marco, "Farsite simulations for cost-efficient wildland fire planning: Case studies in Spain," Forest Ecology and Management, vol. 234, no. 1, pp. 217-217, Nov. 2006. [Online]. Available: http://linkinghub.elsevier.com/retrieve/pii/S0378112706007845

[12] B. Arca, P. Duce, M. Laconi, G. Pellizzaro, M. Salis, and D. Spano, "Evaluation of FARSITE simulator in mediterranean maquis," International Journal of Wildland Fire, vol. 16, no. 5, p. 563, Oct. 2007. [Online]. Available: http://www.publish.csiro.au/?paper=WF06070

[13] E. Chuvieco and J. Salas, "Mapping the spatial distribution of forest fire danger using GIS," International journal of geographical information systems, vol. 10, no. 3, pp. 333-345, Feb. 1996.

[14] J. San-Miguel-Ayanz, P. Barbosa, G. Schmuck, G. Libert, and J. Meyer-Roux, "AGILE 2003: 6th AGILE conference on geographic information science." Lyon,France: PPUR presses polytechniques, 2003.

[15] J. González, M. Palahí, A. Trasobares, and T. Pukkala, "A fire probability model for forest stands in catalonia (north-east Spain)," Annals of Forest Science, vol. 63, no. 2, p. 8, Feb. 2006.

[16] P. Gregori, P. Juan, J. Mateu, F. Saura, and C. A., Modelos espacio-temporales para la evaluacón y caracterización de índices de riesgo de incendios forestales en la Comunidad Valenciana. Davalos-Fletcher, 2006.

[17] C. Van Wagner, "Conditions for the start and spread of crown fire," Canadian Journal of Forest Research, vol. 7, no. 1, pp. 23-34, Mar. 1977. [Online]. Available: http://www.nrcresearchpress.com/doi/abs/10.1139/x77-004

[18] J. González and T. Pukkala, "Characterization of forest fires in catalonia (north-east Spain)," European Journal of Forest Research, vol. 126, no. 3, pp. 421-429, Jun. 2007. [Online]. Available: http://www.springerlink.com/index/10.1007/s10342-006-0164-0

[19] A. Vázquez, "Spatial distribution of forest fires in sierra de gredos (Central Spain)," Forest Ecology and Management, vol. 147, no. 1, pp. 55-65, Jun. 2001. [Online]. Available: http://linkinghub.elsevier.com/retrieve/pii/S0378112700004369

[20] P. Teensma, "Fire history and fire regimes of the central western cascades of oregon," Ph.D. dissertation, University of Oregon, Eugene, 1987.

[21] F. Lloret, E. Calvo, X. Pons, and R. Díaz-Delgado, "Wildfires and landscape patterns in the eastern iberian peninsula," Ecological Research, vol. 17, no. 8, pp. 745-759, Dec. 2003.

[22] G. E. Sakr, I. H. Elhajj, and G. Mitri, "Efficient forest fire occurrence prediction for developing countries using two weather parameters," Engineering Applications of Artificial Intelligence, vol. 24, no. 5, pp. 888-894, Aug. 2011. [Online]. Available: http: //linkinghub.elsevier.com/retrieve/pii/S0952197611000418

[23] P. Andrews, BEHAVE : Fire Behavior Prediction and Fuel Modeling System - BURN Subsystem, Part 1. The Bark Beetles, Fuels, and Fire Bibliography, 1986.

[24] M. Mermoz, T. Kitzberger, and T. T. Veblen, "Landscape influences on occurrence and spread of wildfires in patagonian forests and shrublands," Ecology, vol. 86, no. 10, pp. 2705-2715, Oct. 2005. [Online]. Available: http://www.esajournals.org/doi/abs/10.1890/04-1850

[25] M. C. Nunes, M. J. Vasconcelos, J. M. Pereira, N. Dasgupta, R. J. Alldredge, and F. C. Rego, "Land cover type and fire in portugal: Do fires burn land cover selectively?" Landscape Ecology, vol. 20, no. 6, pp. 661-673, Sep. 2005. [Online]. Available: http://www.springerlink.com/index/10.1007/s10980-005-0070-8

[26] M. Chas, "Forest fires in Galicia (Spain): threats and challenges for the future," Journal of Forest Economics, vol. 13, no. 1, pp. 1-5, May 2007. [Online]. Available: http://linkinghub.elsevier.com/retrieve/pii/S1104689907000037

[27] M. Marey, V. Rodríguez, and R. Crecente, "Using GIS to measure changes in the temporal and spatial dynamics of forestland: experiences from north-west Spain," Forestry, vol. 79, no. 4, pp. 409-423, Jun. 2006. [Online]. Available: http://forestry.oxfordjournals.org/cgi/doi/10.1093/forestry/cpl027

[28] L. Serra, P. Juan, D. Varga, J. Mateu, and M. Saez, "Spatial pattern modelling of wildfires in catalonia, spain 2004-2008," Environmental Modelling and Software, 2012. [Online]. Available: http://www.sciencedirect.com/science/article/pii/S1364815212002460

[29] S. Trilles, P. Juan, L. Díaz, and J. Huerta, "Integración de modelos medioambientales en infraestructuras de datos espaciales: un caso de uso en predicción de incendios," Revista Catalana de Geografia, vol. 18, no. 44, Feb. 2011.

[30] I. Masser, A. Rajabifard, and I. Williamson, "Spatially enabling governments through SDI implementation," International Journal of Geographical Information Science, vol. 22(1), pp. 5-20, Jan. 2008. [Online]. Available: http://www.tandfonline.com/doi/abs/10.1080/13658810601177751

[31] A. Rajabifard, M.-E. F. Feeney, and I. P. Williamson, "Future directions for SDI development," International Journal of Applied Earth Observation and Geoinformation, vol. 4, no. 1, pp. 11-22, Aug. 2002. [Online]. Available: http://linkinghub.elsevier.com/retrieve/pii/S0303243402000028 
[32] I. Bishop, F. Escobar, S. Karuppannan, K. Suwarnarat, I. Williamson, P. Yates, and H. Yaqub, "Spatial data infrastructures for cities in developing countries: Lessons from the bangkok experience," Cities, vol. 17(2), pp. 85-96, Apr. 2000. [Online]. Available: http://linkinghub.elsevier.com/retrieve/pii/S0264275100000044

[33] D. Nebert, Developing Spatial Data Infrastructures: The SDI Cookbook, 2004.

[34] G. Percival, “Open geospatial consortium inc. date: 2008-11-11. reference number: OGC 08-062r4. version: 2.0," OGC Reference Model, Tech. Rep., 2008.

[35] L. Díaz, C. Granell, M. Gould, and J. Huerta, "Managing user-generated information in geospatial cyberinfrastructures," Future Generation Computer Systems, vol. 27(3), pp. 304-314, Mar. 2011. [Online]. Available: http://linkinghub.elsevier.com/retrieve/pii/S0167739X1000172X

[36] L. Bernard, I. Kanellopoulos, A. Annoni, and P. Smits, "The European geoportal-one step towards the establishment of a European spatial data infrastructure," Computers, Environment and Urban Systems, vol. 29(1), pp. 15-31, Jan. 2005

[37] P. Schut, "Opengis web processing service version 1.0.0.” OpenGeospatial Consortium, 2008.

[38] C. D. Michaelis and D. P. Ames, "Evaluation and implementation of the OGC web processing service for use in client-side GIS," GeoInformatica, vol. 13, no. 1, pp. 109-120, Mar. 2009. [Online]. Available: http://www.springerlink.com/index/10.1007/s10707-008-0048-1

[39] C. Kiehle, "Business logic for geoprocessing of distributed geodata," Computers \& Geosciences, vol. 32, no. 10, pp. 1746 - 1757, Dec. 2006. [Online]. Available: http://linkinghub.elsevier.com/retrieve/pii/S0098300406000756

[40] C. Yang, W. Li, J. Xie, and B. Zhou, "Distributed geospatial information processing: sharing distributed geospatial resources to support Digital Earth," International Journal of Digital Earth, vol. 1(3), pp. 259-278, Sep. 2008. [Online]. Available: http://www.tandfonline.com/doi/abs/10.1080/ 17538940802037954

[41] D. McInerney, L. Bastin, L. Diaz, C. Figueiredo, J. Barredo, and J. San-Miguel Ayanz, "Developing a forest data portal to support multi-scale decision making," IEEE Journal of Selected Topics in Applied Earth Observations and Remote Sensing, vol. 5, no. 1, pp. 1-8, Apr. 2012. [Online]. Available: http://ieeexplore.ieee.org/lpdocs/epic03/wrapper.htm?arnumber=6202366

[42] Y. Heymann, C. Steenmans, G. Croissille, and M. Bossard, “Corine land cover - technical guide,” Tech. Rep., 1994.

[43] E. E. Agency, "Technical report no 17/2007. clc2006 technical guidelines," Tech. Rep., 2007.

[44] J. Mller and C. Díaz-Avalos, "Structured spatio-temporal shot-noise cox point process models, with a view to modelling forest fires," Scandinavian Journal of Statistics, vol. 37, no. 1, pp. 2-25, Mar. 2010. [Online]. Available: http://doi.wiley.com/10.1111/j.1467-9469.2009.00670.x

[45] J. Mateu, J. Usó, and F. Montes, “The spatial pattern of a forest ecosystem,” Ecological Modelling, vol. 108, no. 1-3, pp. 163-174, May 1998. [Online]. Available: http://linkinghub.elsevier.com/retrieve/pii/S0304380098000271

[46] ser. Lecture Notes in Statistics. Springer-Verlag, 2006, vol. 185.

[47] N. Picard, A. Bar-hen, F. Mortier, and J. Chadeuf, "The multi-scale marked area-interaction point process: A model for the spatial pattern of trees," Scandinavian Journal of Statistics, vol. 36, no. 1, pp. 23-41, Jan. 2009.

[48] A. Baddeley and R. Turner, "Spatstat: An r package for analyzing spatial point patterns," J. Stat. Softw., vol. 12, no. 6, pp. 1-42, Jan. 2005.

[49] J. Illian, A. Penttinen, H. Stoyan, and D. Stoyan, Statistical Analysis and Modelling of Spatial Point Patterns, 1st ed. Wiley-Interscience, 2008.

[50] A. Baddeley, Analysing Spatial Point Patterns in R. Perth, CSIRO and University of Western Australia, 2008.

[51] B. D. Ripley, "The second-order analysis of stationary point processes," Journal of Applied Probability, vol. 13, no. 2, pp. 255-266, Jun. 1976.

[52] B. Widom, "New model for the study of Liquid-Vapor phase transitions," The Journal of Chemical Physics, vol. 52, no. 4, p. 1670 , 1970.

[53] A. Baddeley and M. Van Lieshout, "Area-interaction point processes," Annals of the Institute of Statistical Mathematics, vol. 47, no. 4, pp. 601-619, Dec. 1995.

[54] I. E. Directive, "Directive 2007/2/ec of the European parliament and of the council of 14 march 2007 establishing an infrastructure for spatial information in the European Community (INSPIRE)," Official Journal of the European Union, Tech. Rep., 2007.

[55] L. Díaz, S. Schade, S. Geertman, W. Reinhardt, and F. Toppen, "GEOSS service factory: Assisted publication of geospatial content," Proceedings of the 14th AGILE International Conference on Geographic Information Science - Advancing Geoinformation Science for a Changing World, Utrecht, vol. 1, pp. 423-442, Dec. 2011.

[56] S. Trilles, L. Díaz, J. Gil, and J. Huerta, "Assisted generation and publication of geospatial metadata," Proceedings of the 15th AGILE International Conference on Geographic Information Science: Bridging the Geographic Information Sciences, Avignon, 2012.

[57] A. Tamayo, C. Granell, L. Diaz, and J. Huerta, "Building compact standard-based geoprocessing mobile clients," Proceedings of the 15th AGILE International Conference on Geographic Information Science: Bridging the Geographic Information Sciences, Avignon, 2012. 

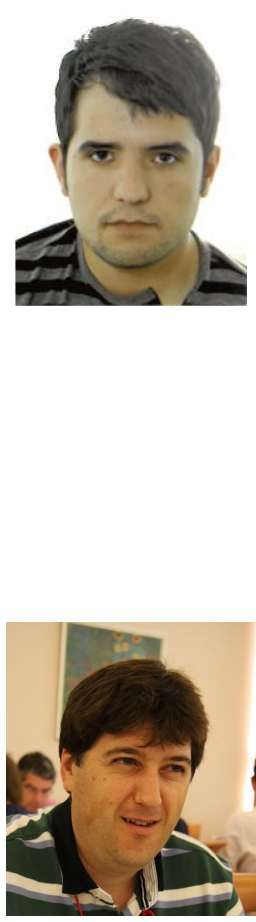

space-time processes.

Sergio Trilles received his M.Sc. in computer science from the Jaume I University in 2010. Currently he is a researcher at the GEOTEC group is apart of the Institute of New Imaging Technologies I University and he is pursuing his Ph.D. in integration of geospatial information from Jaume I University. His research areas include geoprocesing, metadata generation and publication and Java technology.

Pablo Juan graduated in Chemistry, Faculty of Chemistry, University of Castellón (1997) and obtained his M.Sc. by thesis Caracterización de la Agresividad de la Lluvia en la Provincia de Castellón (2001) and the doctoral degree Statistics Técnicas geoestadísticas espectrales. Análisis de la estacionariedad e independencia (2005) from Universitat Jaume I of Castellón where he is currently Assistant Professor of Statistics, Department of Mathematics. His main areas of methodological and practical research interest concern spatial statistics, in particular spatial point processes and spatio-temporal geostatistics, motivated by applications in the environmental sciences (forest fires, forest species, wild animals, soil contamination, air pollution, etc.) and in statistical quality control. He has participated in R\&D projects at the group of Jorge, actually developing selected main problems in stochastic

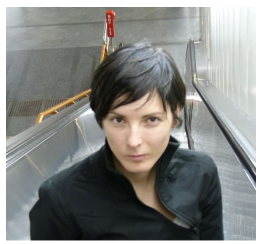

Laura Díaz graduated in Computer Engineering (2000) from the Universitat de València and obtained her MSc in Intelligent Systems (2008) and the doctoral degree in Geospatial Science (2010) from Universitat Jaume I of Castellón where she is currently a research associate. She has participated in R\&D projects at the Institute of Robotics at the Universitat de València and GIS companies such as Geodan (The Netherlands) and Iver TI (Spain). Furthermore, she participated in research stages at Institute of GeoInformatics (University of Mnster) and Institute of Environment and Sustainability (Joint Research Centre). Her main research interests are in the field of Geospatial Information Infrastructures and User generated content, in particular she is investigating novel approaches for improving geospatial content integration and publication, distributed geoprocessing and service interoperability.

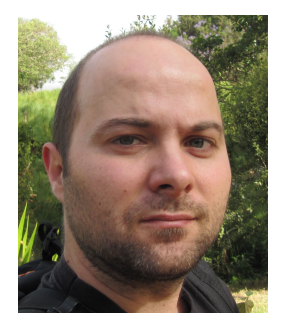

Pau Aragó is a PhD Student at Jaume I University, Spain. He has a Background in forestry and a Master in Geospatial Technologies. His research is focus in Volunteered Geographic information and user assistant to create new spatial Data. He also collaborates in forest fires spatial technologies with other colleges. 


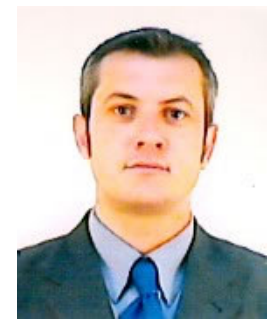

Joaquín Huerta is a professor in the Department of Information Systems at UJI, where he teaches GIS and Internet Technologies. He holds a PhD in Computer Science from Jaume I University. He is Co-director of the Master in Geospatial Technologies funded by the Erasmus Mundus program and Director of the PhD Program on Integration of Geospatial Information. He is leading and has led several important research projects including EU projects as EUROGEOSS (FP7) and eSDI-NET+ (FP6) and a Spanish projects as "España Virtual" funded by the Cenit Programme. His main research activities are in computer science, networks and Internet technologies, Web2.0, Context aware systems, multi-resolution modelling and sensor networks. In addition to academic activities, Dr. Huerta is a founding board member of an Internet service provider and, thus, possesses considerable business experience as well as experience in systems integration. 


\section{List OF FIGURES}

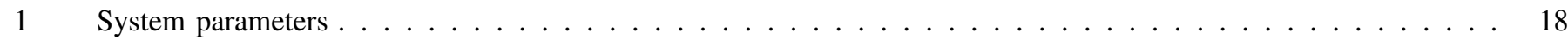

2 Service perspectives: types, design and implementation. INSPIRE Service types and FirePredic service deployment 19

3 Sequence diagram for the execution of the Fire Risk - WPS . . . . . . . . . . . . . . . . . 20

$4 \quad$ Situation of the area analyzed, Castellón de la Plana province . . . . . . . . . . . . . . . . . . . . 21

$5 \quad$ Visual representation of the input parameters are, a) the contour, b) the wildfire c) the orientation, d) the land use, e) the elevation and $\mathrm{f}$ ) the slope . . . . . . . . . . . . . . . . . . . . . 22

6 Graph of all models. a) Graph of Poisson model with polynomial x, y. b) Graph of Poisson model with polynomial $x, y, 2$. c) Graph of Poisson model with elevation covariate. d) Graph of Poisson model with land use covariate. e) Graph of Poisson model with all covariates. f) Graph of Area-Interaction model with polynomial x, y. g) Graph of Area-Interaction model with elevation covariate. h) Graph of Area-Interaction model with land use covariate. i) Graph of Area-Interaction model with all covariates . . . . . . . . . . . . . . . . . . . . . . . . . . . . . . .

$7 \quad$ Visual representation of the contents of a KML point . . . . . . . . . . . . . . . . . . . . . . . . . 24

$8 \quad$ Risk prediction maps. a) Risk prediction map of Poisson model with polinomial x, y. b) Risk prediction map of Poisson model with polynomial $x, y, 2$. c) Risk prediction map of Poisson model with elevation covariate. d) Risk prediction map of Poisson model with land use covariate. e) Risk prediction map of Poisson model with all covariates. f) Risk prediction map of Area-Interaction model with polynomial x, y. g) Risk prediction map of Area-Interaction model with elevation covariate. h) Risk prediction map of Area-Interaction model with land use covariate. i) Risk prediction map of Area-Interaction model with all covariates . . . . . . . . . . . . . . . 25 


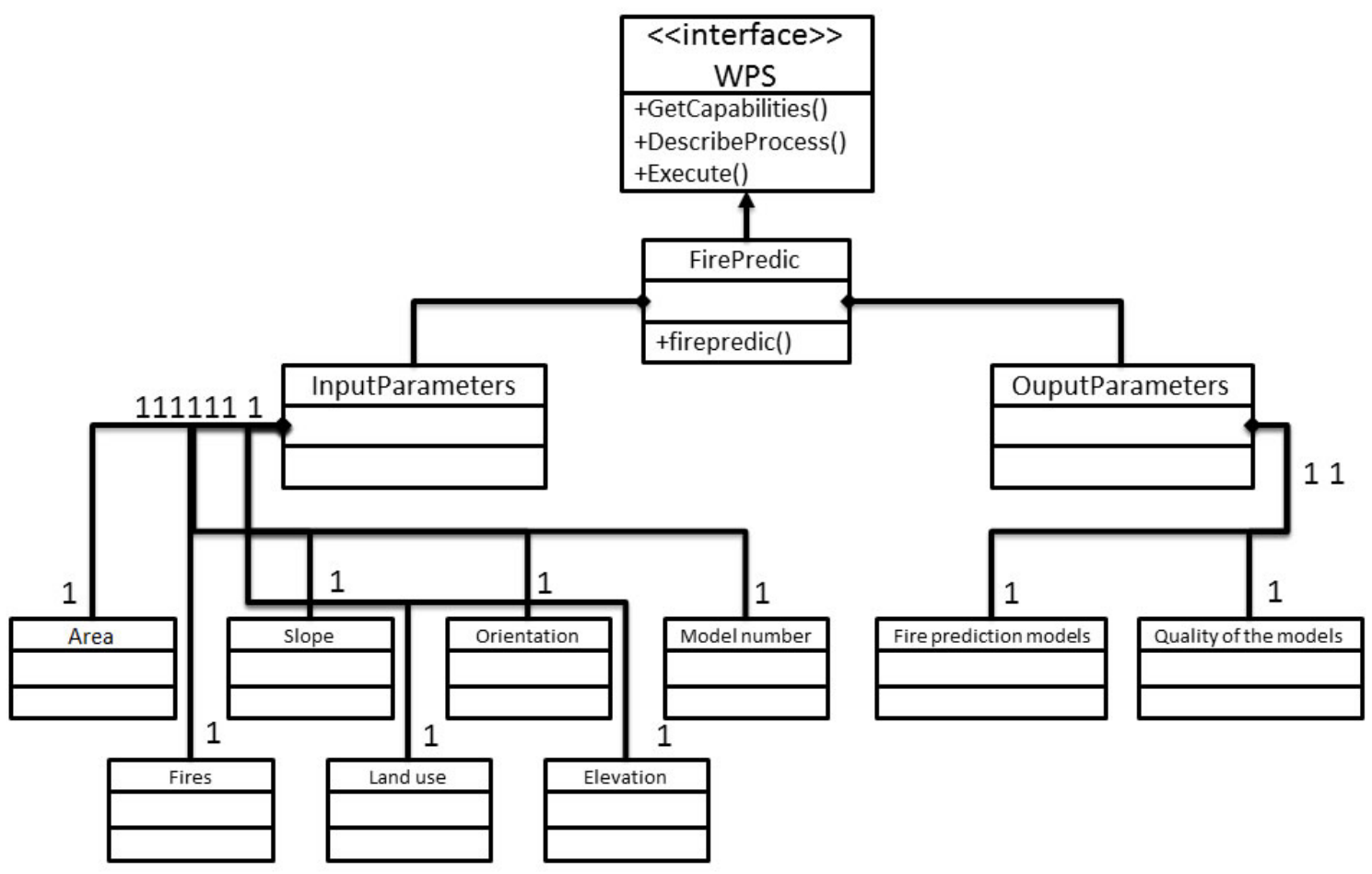

Fig. 1. System parameters 


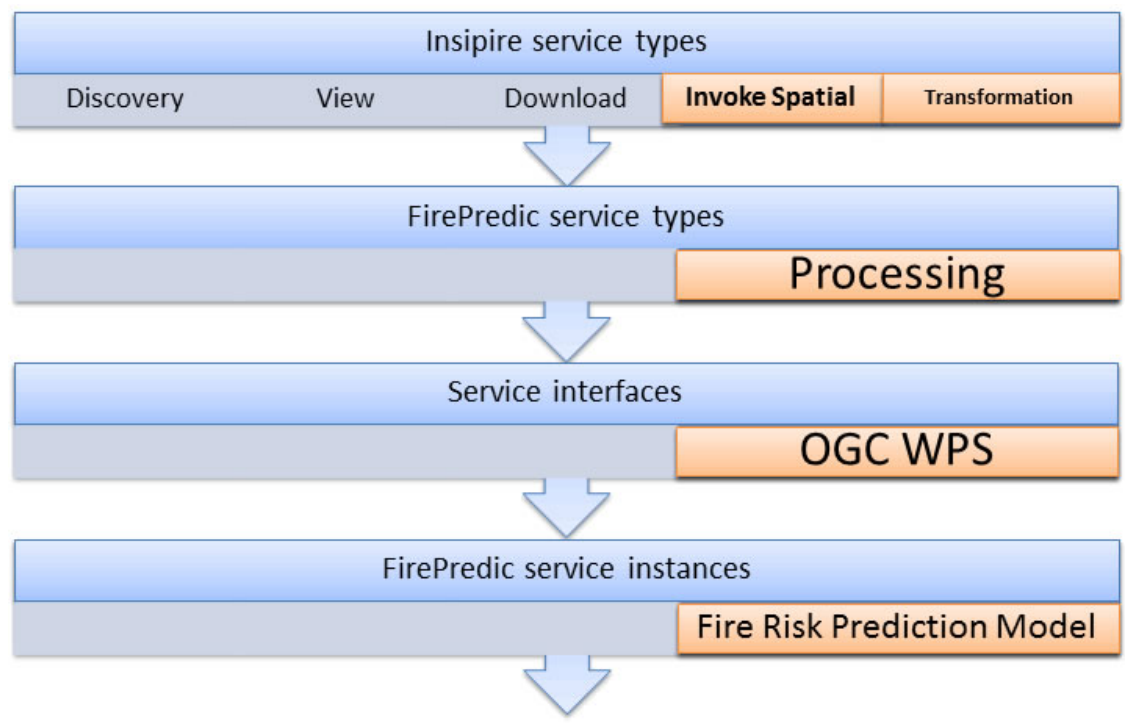

Fig. 2. Service perspectives: types, design and implementation. INSPIRE Service types and FirePredic service deployment 


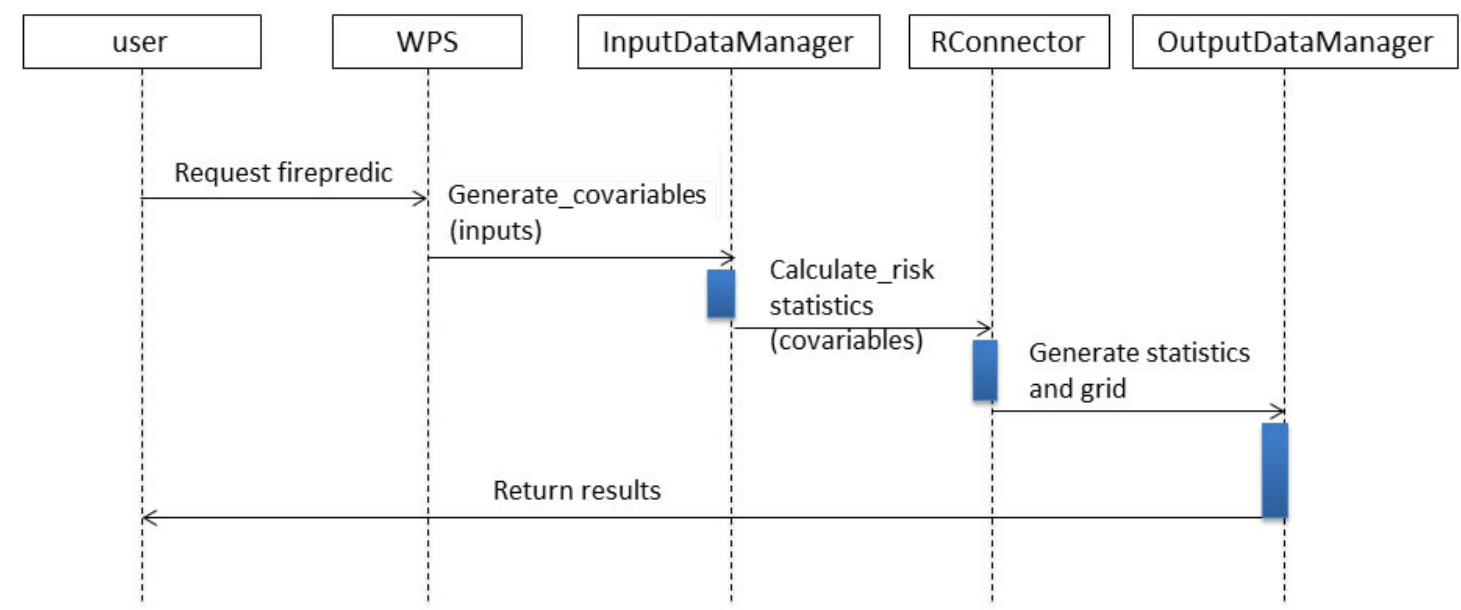

Fig. 3. Sequence diagram for the execution of the Fire Risk - WPS 


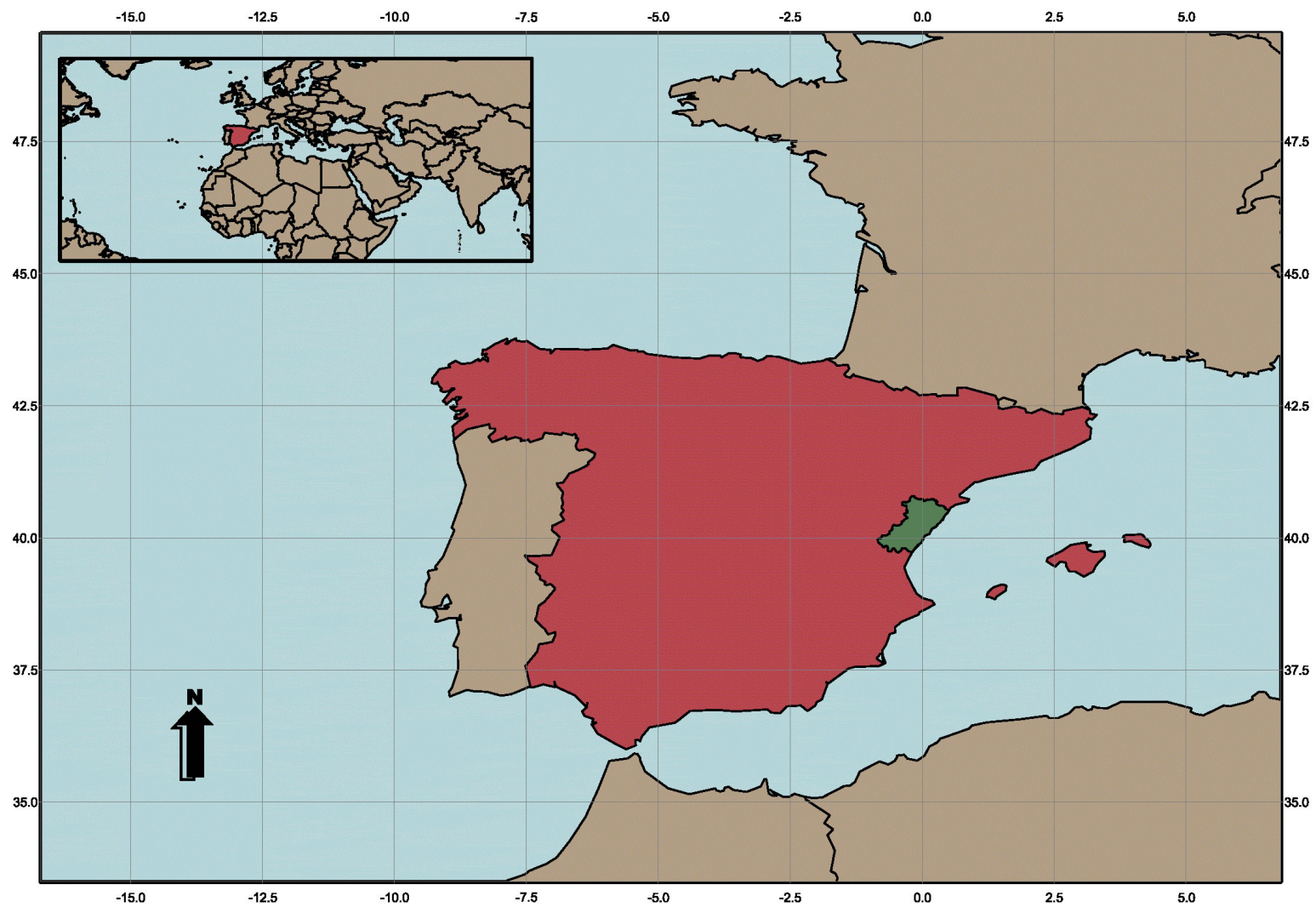

Fig. 4. Situation of the area analyzed, Castellón de la Plana province 


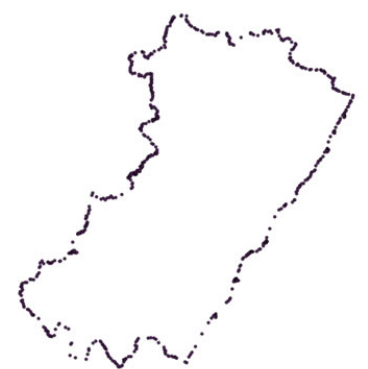

a)

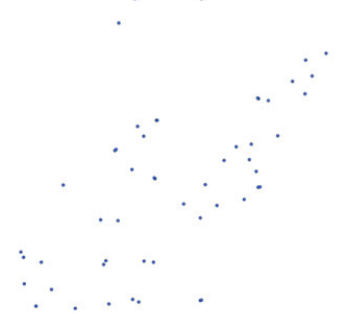

b)

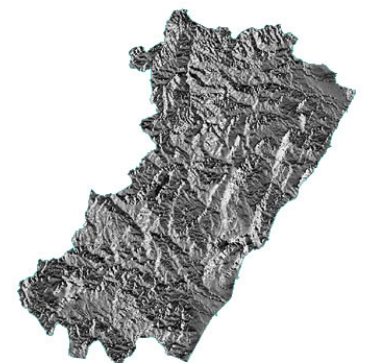

c)

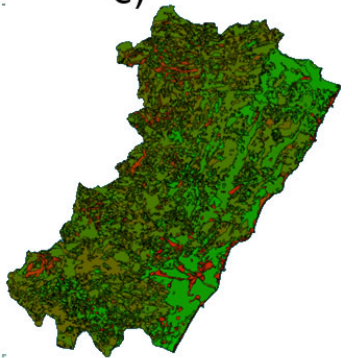

d)

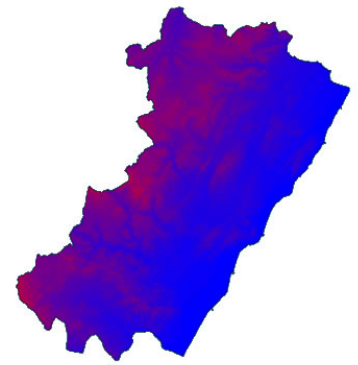

e)

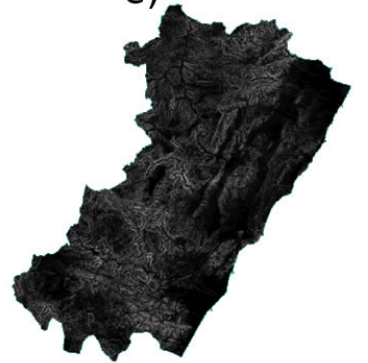

f)

Fig. 5. Visual representation of the input parameters are, a) the contour, b) the wildfire c) the orientation, d) the land use, e) the elevation and f) the slope 


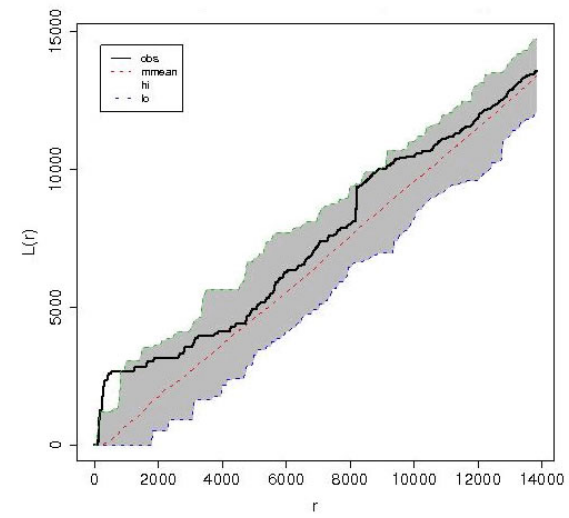

a)

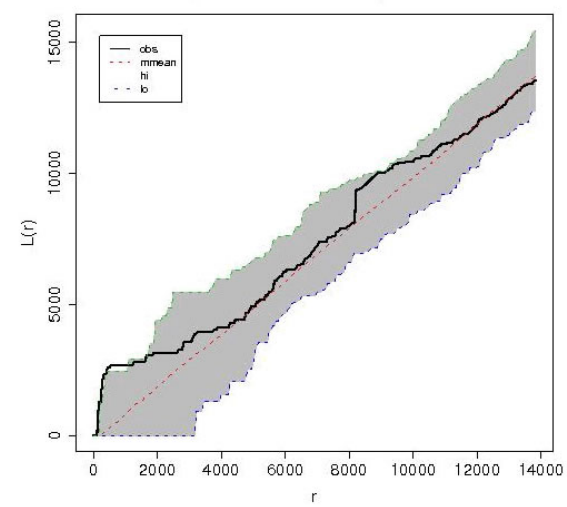

d)

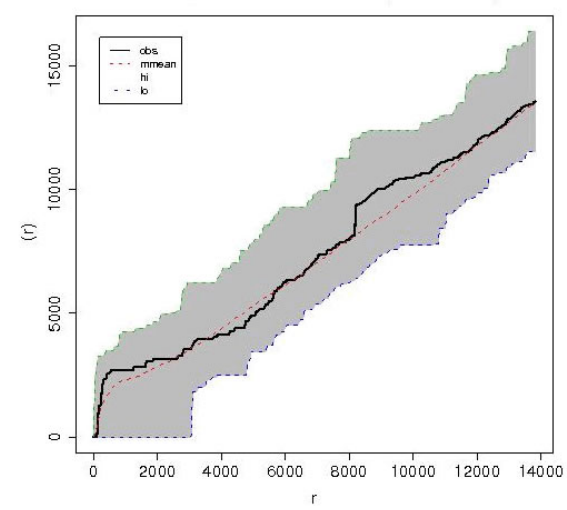

g)

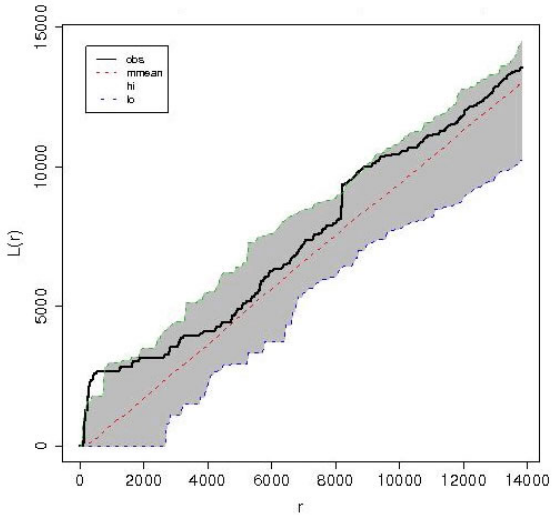

b)

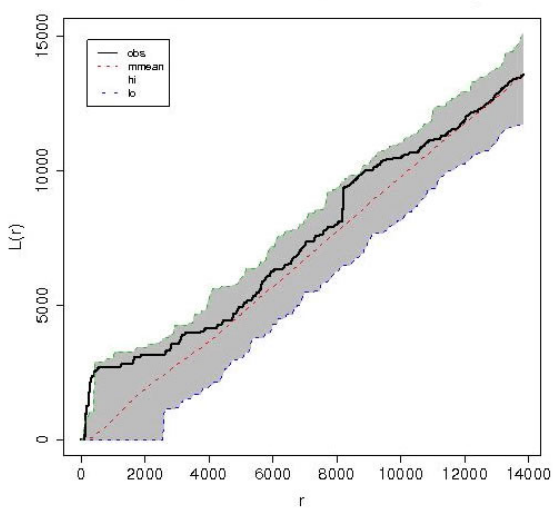

e)

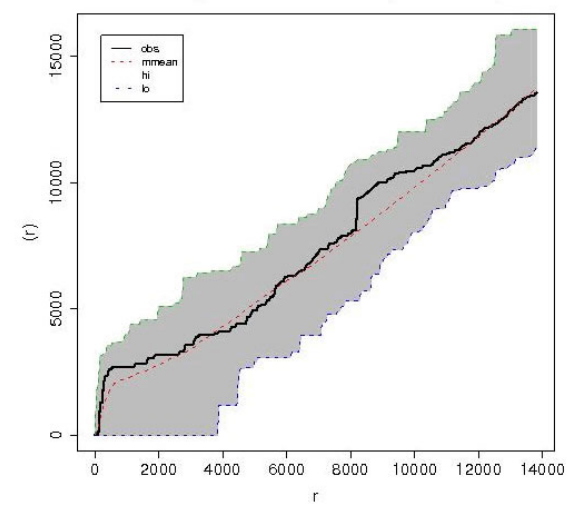

h)

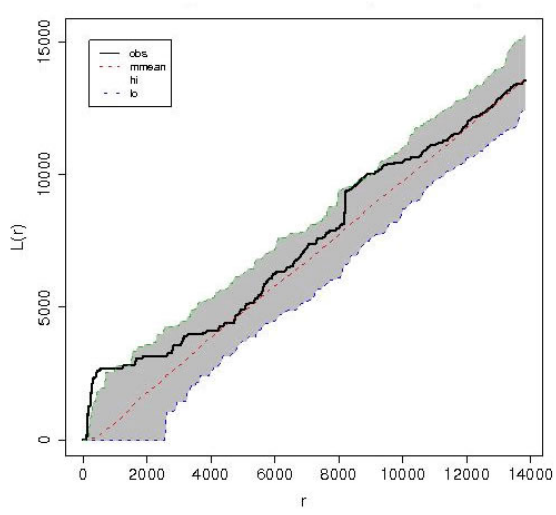

c)

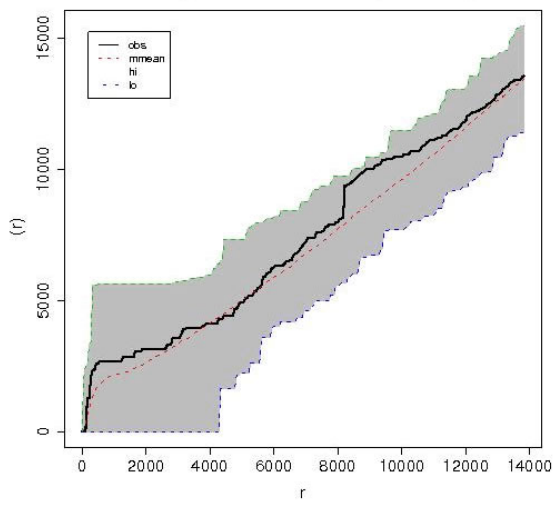

f)

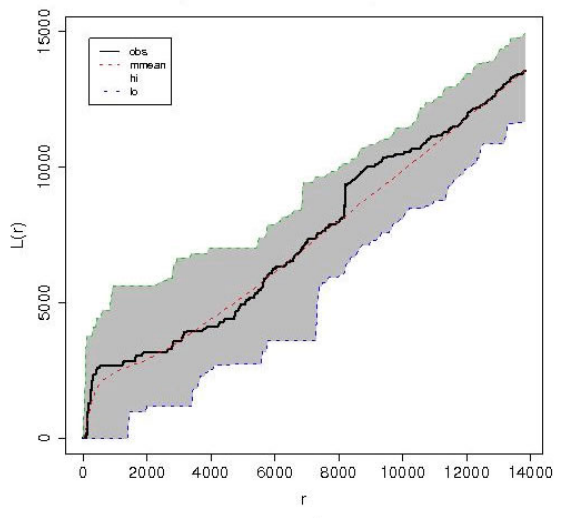

i)

Fig. 6. Graph of all models. a) Graph of Poisson model with polynomial x, y. b) Graph of Poisson model with polynomial $x, y$, 2. c) Graph of Poisson model with elevation covariate. d) Graph of Poisson model with land use covariate. e) Graph of Poisson model with all covariates. f) Graph of Area-Interaction model with polynomial $x, y . g)$ Graph of Area-Interaction model with elevation covariate. h) Graph of Area-Interaction model with land use covariate. i) Graph of Area-Interaction model with all covariates 


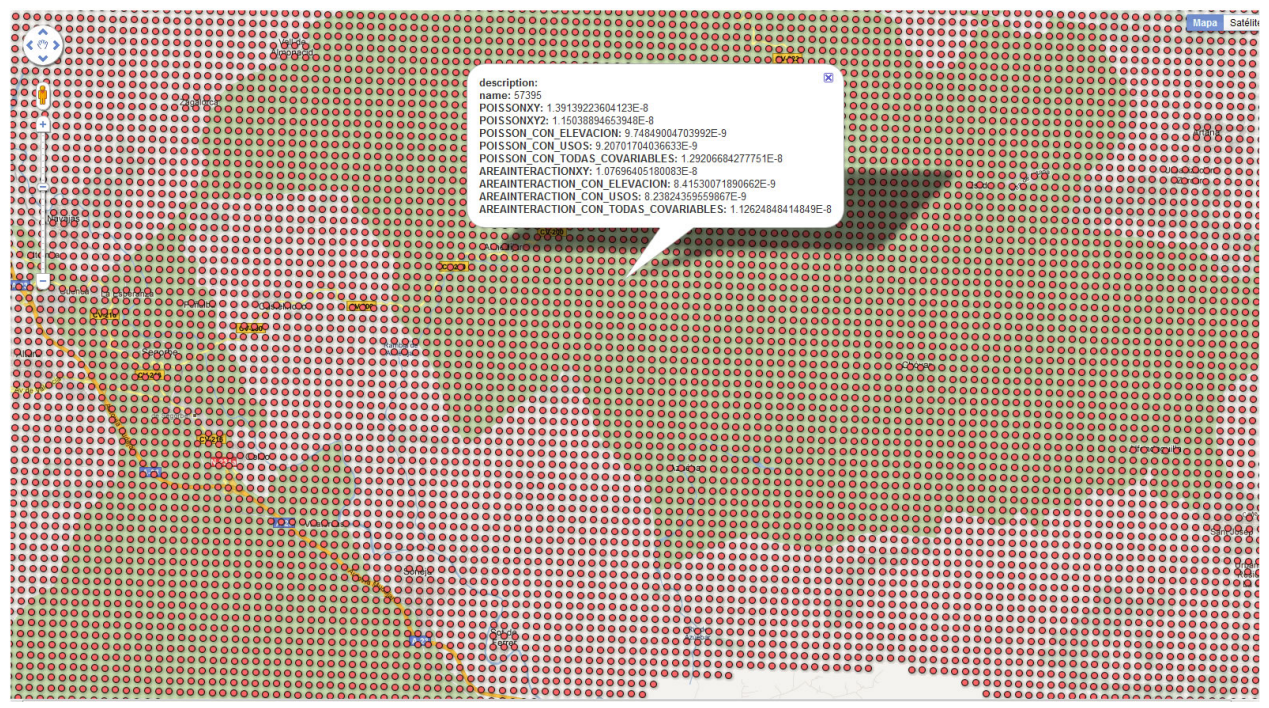

Fig. 7. Visual representation of the contents of a KML point 


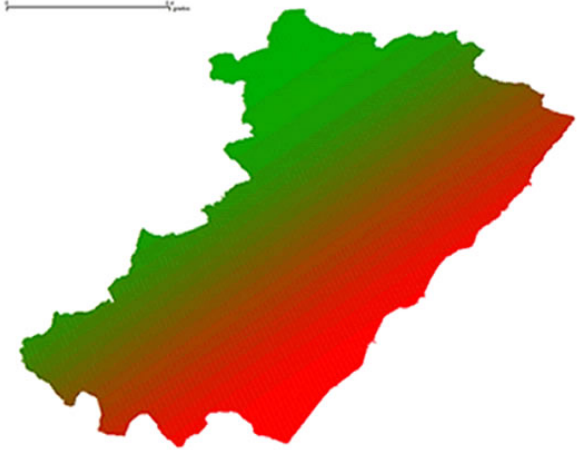

a)

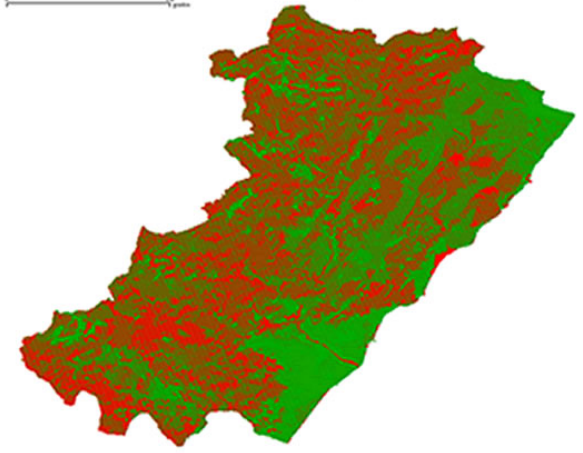

d)

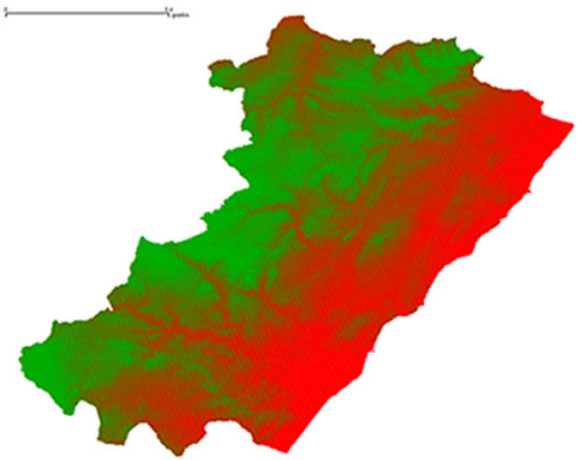

g)

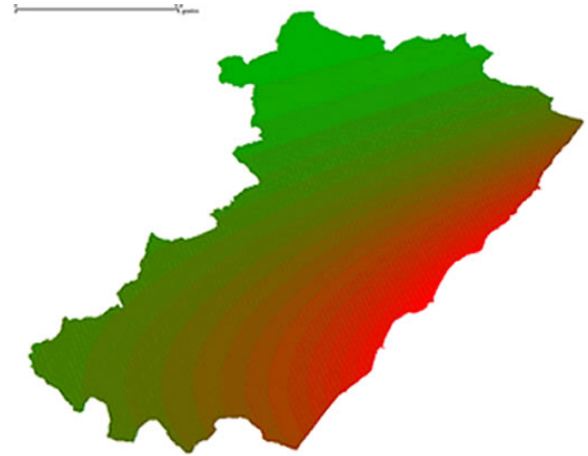

b)

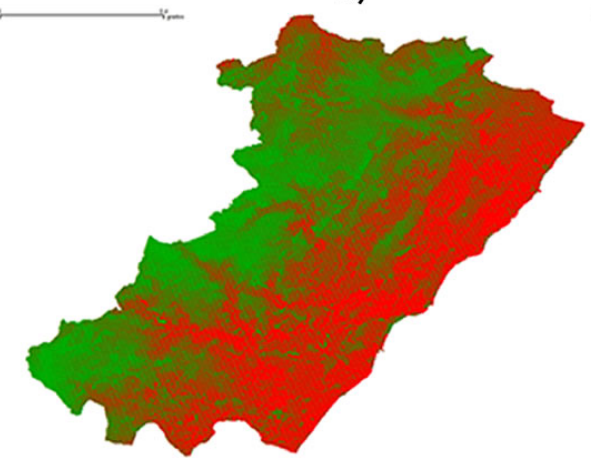

e)

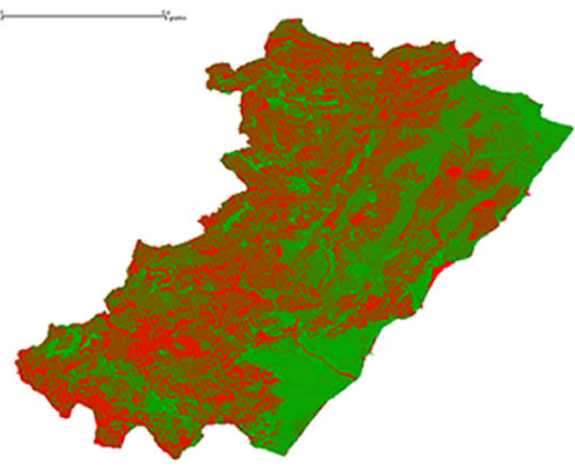

h)

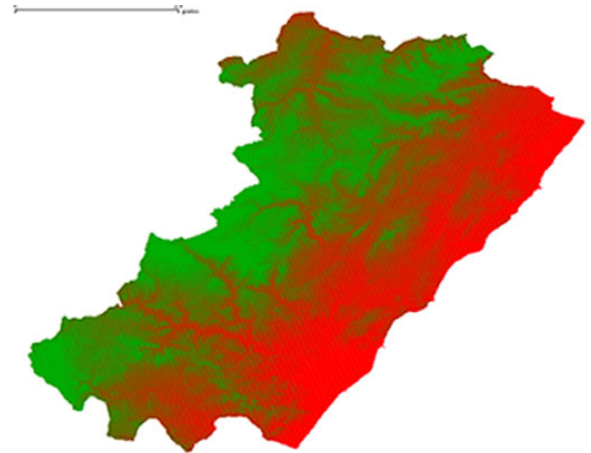

c)

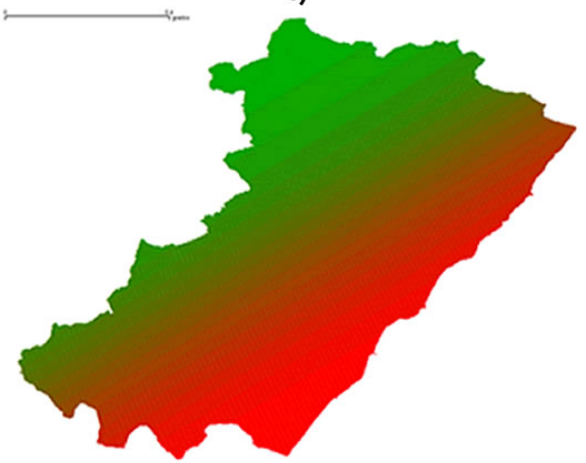

f)

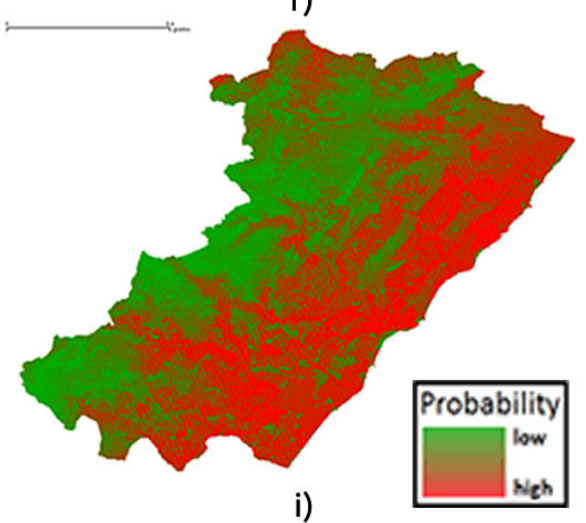

Fig. 8. Risk prediction maps. a) Risk prediction map of Poisson model with polinomial $\mathrm{x}, \mathrm{y} . \mathrm{b}$ ) Risk prediction map of Poisson model with polynomial $x$, $y$, 2. c) Risk prediction map of Poisson model with elevation covariate. d) Risk prediction map of Poisson model with land use covariate. e) Risk prediction map of Poisson model with all covariates. f) Risk prediction map of Area-Interaction model with polynomial x, y. g) Risk prediction map of Area-Interaction model with elevation covariate. h) Risk prediction map of Area-Interaction model with land use covariate. i) Risk prediction map of Area-Interaction model with all covariates 


\section{LIST OF TABLES}

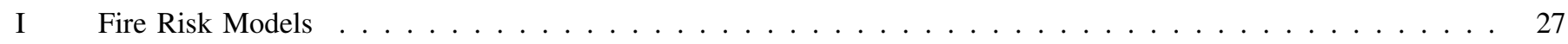

II Times for each method. . . . . . . . . . . . . . . . . . . . . . . . . . . . . . . . . . 28 


\begin{tabular}{||l|c||}
\hline \hline 1 & Poisson polynomial $\mathrm{x}, \mathrm{y}$ \\
\hline 2 & Poisson polynomial $\mathrm{x}, \mathrm{y}, 2$ \\
\hline 3 & Poisson with elevation covariate \\
\hline 4 & Poisson with land use covariate \\
\hline 5 & Poisson with all covariates \\
\hline 6 & Area-Interaction polynomial $\mathrm{x}, \mathrm{y}$ \\
\hline 7 & Area-Interaction with elevation covariate \\
\hline 8 & Area-Interaction with land use covariate \\
\hline 9 & Area-Interaction with all covariates \\
\hline
\end{tabular}

$$
\text { TABLE I }
$$

FIRE RISK MOdeLS 


\begin{tabular}{||l|c|r||}
\hline \hline Number & Model & Time \\
\hline 1 & Poisson polynomial $\mathrm{x}, \mathrm{y}$ & $42 \mathrm{~s}$ \\
\hline 2 & Poisson polynomial $\mathrm{x}, \mathrm{y}, 2$ & $42 \mathrm{~s}$ \\
\hline 3 & Poisson with elevation covariate & $1 \mathrm{~m} \mathrm{31} \mathrm{s}$ \\
\hline 4 & Poisson with land use covariate & $1 \mathrm{~m} 29 \mathrm{~s}$ \\
\hline 5 & Poisson with all covariates & $1 \mathrm{~m} \mathrm{31} \mathrm{s}$ \\
\hline 6 & Area-Interaction polynomial x, y & $4 \mathrm{~h} 51 \mathrm{~m} 55 \mathrm{~s}$ \\
\hline 7 & Area-Interaction with elevation covariate & $2 \mathrm{~h} 13 \mathrm{~m} \mathrm{30} \mathrm{s}$ \\
\hline 8 & Area-Interaction with land use covariate & $2 \mathrm{~h} 20 \mathrm{~m} 15 \mathrm{~s}$ \\
\hline 9 & Area-Interaction with all covariates & $2 \mathrm{~h} 20 \mathrm{~m} \mathrm{38} \mathrm{s}$ \\
\hline \hline
\end{tabular}

TIMES FOR EACH METHOD. 